\title{
Research on Backwash Effect of Language Dialogue on Chinese Language Teaching
}

\author{
Zengzhi Wang \\ Xi'an Peihua University, Xi'an, Shanxi, China, 710125
}

Keywords: Backwash Effect, Language Dialogue, Chinese Language Teaching

\begin{abstract}
Tests have a backwash effect on teaching, the positive effect can promote students to study hard and teachers to improve teaching work; while the negative effect is apt to cause the teaching and learning bias. Therefore, it is necessary to improve the test of the positive anti-dial function and reduce its negative effect. Test should have clear purpose, with the correct theory as a guide, take a combination of direct test and indirect test to minimize the objective test questions, and to increase subjective questions.
\end{abstract}

\section{Introduction}

"Backwash" refers to the impact of language testing on teaching and learning (Hughes 1989), and can be either positive or negative. Although the impact of different types of tests and different test content on teaching can vary greatly, there is no doubt that the counter-dialing effect exists. This article analyzes the problems existing in language testing in the past, explores corresponding to the testing, puts forward the preferential principle of establishing the anti-pullback effect of the test on teaching and puts forward my own opinion on how to make the test of the language test positive.

\section{The Problems in Previous Language Tests}

"High score low energy" seems to be the most common phenomenon among current students. There are two possible reasons for the "high and low energy" phenomenon: 1. "High score and low energy" can be regarded as the product of examination-oriented education in schools. Propositions and judgments unscientific is the main reason for the "high score low energy" phenomenon. Some exams are overrepresented, most of them are multiple-choice questions written with standard answers and the model is rigid. Therefore, the test scores difficult to reflect the true level of students and ability.

The problem of recognizing the value of scores: At present, the understanding of schools and employers is not uniform for the value of test scores. Top-notch students in schools often fail to recognize the society. The reason is that the training objectives requested by society do not match the scores earned by students. Employers are concerned about the overall quality of students, and schools to judge the strengths and weaknesses of students tend to focus on student scores; employers first pay attention to the ideological and moral character of students, social activities and organizational skills, and secondly is their academic performance. This shows that the social requirements of students and students have a direct relationship between the quality of education. For example, the test of Chinese language emphasizes the test of language knowledge, the reliability and validity of the answer are often controversial, the pertinence is not strong and the lack of flexibility cannot reflect the students' ability to actually use the language, and to a certain extent deviate from the Chinese language teaching Training objectives and training characteristics.

\section{The Backwash Effect of Language Test Dialogue on Chinese Language Teaching}

First test should be adapted to the needs of society. The specific requirements of language testing are: language testing should focus on examining students' ability to actually use, to achieve scientific and objective unity, and have a certain degree of standardization. At present, there is a 
considerable distance between the teaching methods of Chinese teaching in schools and the needs of the society. In particular, the prominent reflection is that the students' language ability is very poor. In many cases, students' language proficiency cannot meet the employer's job requirements. The fundamental reason lies in the fact that school education has its own emphasis on theory and application of lightness. The emphasis on books and light practical abuses, combined with many other factors, totally ignores the social demand for students' foreign language ability. Therefore, in my opinion, to strengthen the pertinence of language testing, increase the strength of applied testing, and adjust the subjective and objective questions, that is, the ratio of basic knowledge and basic skills, so as to keep the content of language testing in keeping with the development of the times and focusing on actual results, Prominent application of features, and strive to enable students to test their performance consistent with their ability to use the language to enable students to the actual ability to fully reflect the test is the focus of language testing reform.

Backwash refers not only to the impact of the test on teaching and foreign language learning, but also on the impact of language testing on curriculum, educators and personnel training. Alder-son pointed out that after so many years of research, we have clearly seen that the effect of backwash has gone beyond the test itself, that it is related to the curriculum, the behavior of teachers and students both inside and outside class, the use of scores are inextricably linked. The impact or reaction of language tests on teaching (including teaching and learning) may be positive, positive, negative, or negative. Although different scholars express different roles in backwashing, they are all used to explain the duality of language testing in teaching. Scientific and fair testing can guide the teaching activities correctly and make the teaching more perfect so as to improve the teaching quality. Conversely, unscientific or improper tests can mislead teaching and hinder teaching. Therefore, to improve the quality of teaching, we must carefully study the test of the teaching of the reverse function. Take measures to improve the positive anti-dial function, to avoid or reduce the negative test negative anti-dial function.

\subsection{Positive Backwash Effect}

First of all, for teachers, scientific testing can promote the teaching of teachers. Teachers can take full advantage of the feedback test information to understand the learning of students and find their own deficiencies in order to adjust teaching strategies and teaching content. It should be acknowledged that the test results have a certain impact on teachers, the test results to some extent reflects the teaching level and teaching attitude of teachers. Therefore, testing can promote teachers to improve their own level of business and ability. Second, for students, scientific and impartial testing can objectively and accurately evaluate a student's language ability. Students can learn from their mastery of learning content, find gaps, lessons learned, facilitate the future learning process targeted, and promote learning.

\subsection{Negative Backwash Effect}

First of all, from a teacher's point of view, they tend to think of tests as / baton 0, deviating teaching content from teaching syllabus and affecting normal teaching activities. Take the National Students' Chinese CET4 and CET6 exams as an example. Some schools regard the passing rates of CET and CET as the standard of teaching for teachers. In order to improve students 'test scores, teachers often neglect to train their students' language ability and communicative competence. The teaching is completely based on the examination and the cart before the horse, and deviates from the general direction of quality education. Second, from the students' point of view, the test results scores have a great influence on their motivation and learning attitude. Many students even give up their textbooks for examinations, busy with questions, do not attach importance to language communication and the use of capacity-building. What is basically what to learn test, is entirely to meet the exam. In short, the positive and negative effects of language testing on Chinese language teaching coexist. The crux of the problem is how to reduce the negative backwash effect, maximize positive counter-dialing, better serve teaching activities bring a good guide to teaching. 


\section{Enhance the Positive Test of the Language Test}

Examination can only be an effective measure if the quality of the exam is guaranteed. Scientific and fair test should have high reliability and validity. The reliability of the language test refers to the reliability and stability of the test result. The higher the reliability of the test, the more objectively and accurately reflect the language ability of the subject. The validity of a language test is the extent to which an exam reaches its intended test intent. The higher the validity of the test, the more effectively reflect the testees' language use and language communication skills.

Assurance testing of high reliability and high efficiency test workers are pursuing the goal. But this is only an idealized goal. Because of the inherent contradictions between the two, it is impossible for a test to have very high reliability and validity. Any test must be compromised and compromised. Must ensure that the validity requirements, and on this basis, as much as possible the pursuit of reliability.

Clear test purpose each exam, whether small or large, should have a clear goal. For example, the domestic graduate entrance exam, which belongs to the proficiency test, is a test that measures a student's language proficiency and is not a test linked to a specific course. And the usual semester exams are the achievement test, which organizes exams at the end of the class or at the end of the class. Its greatest feature is related to the syllabus, that is, the achievement test should follow what to teach, test what the principle.

Objectives to reduce the objectivity of the subjective test questions Objective test questions mainly examine the subject's ability to recognize language knowledge, it cannot test the students ability to use the integrated language, do not encourage the use of comprehensive or output skills. The subjective questions focus on examining the ability to use language, emphasis on speaking and writing skills. Language testing should be the ability test in the first place, in order to increase the validity of the test.

Using a combination of direct test and indirect test Direct test focuses on the authenticity of the test form, and test content and the environment close, with a clear test objectives. Xiao-Ju Li believes that modern multimedia technology for the highly situational language testing offers the possibility of this situational test can enhance students' interest in learning and motivation. Indirect testing often use a roundabout way to assess the language skills of students. Both tests have their own advantages and disadvantages, only properly used and combined properly to avoid weaknesses.

Using the Correct Theory as guidance the validity of a structure is an important factor in measuring the validity of a test. The so-called structure refers to the theoretical basis of the entire test is to measure the test whether the effective view of language (including the concept of language learning and language use) as the basis. For example, according to Bachman's theoretical model, a person's verbal communication ability consists of three parts: language ability, strategic ability and mental and physical mentality. If you can follow this theoretical model to prepare a language test paper, it has a scientific theoretical basis.

\section{The Priority Principles of Establishing the Anti-pull Back Role of Test on Teaching}

The test scores of any subject cannot avoid the direct or indirect impact on teaching. In the field of testing, it is called backwash. In the actual teaching, the exam may have a positive effect on the backsliding, but it may also have a negative effect on the backsliding. Positive backwashing is conducive to teaching in the right direction, which is a concrete manifestation of the purpose and requirements of the examinations in the examinations. On the contrary, the negative backwashing effect cannot only well reflect the purpose and requirements of teaching but also distort teaching, the so-called "exam-oriented education." Therefore, a good teaching test must not only have a high degree of reliability, validity and feasibility, but also have a positive effect on teaching. The author summarizes many years of teaching experience, and compared some of the experience of brothers and sisters colleges, the proposed language test should use the following questions:

Diversified types of questions: Diversified types of questions make students inconvenient to simulate, avoid the problem-type fixed, avoid studying the "answer skills", and help to unveil the 
exam-oriented education. Such as: fill in the blanks, short answer, information conversion, sorting, matching and so on. The characteristics of these questions are as much as possible to focus on the ability of students to obtain information, so that students can only complete the test topic on the basis of complete grasp of the language information should be obtained.

Substantial reduction of multiple choice questions: shift the focus of testing from the ability of language recognition and guessing to the generalization, judgment, reasoning and expression of language knowledge and skills. A number of multiple-choice questions in the entire test paper in the proportion of not more than $1 / 3$, the rest of the title book needs students to complete the pen.

Increase the proportion of translation: social survey shows that the demand for translation ability is second only to reading, ranking second. This fully demonstrates the importance of translating ability to college students. Therefore, we should strengthen the test of the students' translation skills in the test, especially the test of their translation skills in the special context.

Pay attention to improve the reliability and validity of the test: the reliability of the test refers to the reliability of the test results, that is, test results reflect the actual level of knowledge of the testees; Validity refers to the accuracy of the test, That is, whether the test measures what it wants to measure and whether it has achieved the test purpose it is intended for. In order to scientifically, objectively and impartially measure the academic performance of students, try to improve the reliability and validity of papers.

\section{Conclusions}

The ultimate goal of testing is to serve teaching. As a teacher, it pays attention to the research of the theory of language test and the principle of proposition, and the best balance between the reliability, validity and other evaluation indexes in the process of preparing papers will be more effective in optimizing the quality of Chinese tests Promote the development of Chinese teaching.

\section{References}

[1] Chen Junlin. Negative counter-dialing effect of language testing and foreign language teaching [J]. Journal of Shangqiu Teachers College. 2006 (03). 62-67.

[2] Huang Dayong, Yang Bingjun. Overview of language test backwash effect [J]. Foreign Language Teaching and Research. 2002 (04).50.

[3] Wan Ling. Reflections on testing and counter-dialing [J]. Bilingual Learning. 2007 (04).111.

[4] Lei Wei, Yuan Rong. Backwash Effect of Language Testing and Foreign Language Teaching [J]. Journal of Tianshui Normal University. 2009 (06).55-57.

[5] Song Meiyin. The relationship between language testing and Japanese teaching [J]. Times Education (Education and Teaching). 2010 (07).88.

[6] Hong Xuejiao. Analysis and Analysis of Dialogue Function in Domestic Language Testing [J]. Jiangnan University of Finance and Economics. 2009 (02).12. 